\title{
Effect of incorporation
} of nano-hydroxyapatite particles on the clinical performance of conventional and resin-modified glass ionomer cement in class $V$ cavities: split-mouth, randomized controlled trial

\author{
Zeinab M. Zaki ${ }^{1}$, Maha A. Niazy², Mohamed H. Zaazou', Shaymaa M. Nagii* (D) and Dina W. Elkassas ${ }^{3}$
}

\begin{abstract}
Background: The aim of this study was to compare the clinical performance of Nano-hydroxyapatite-modified conventional glass ionomer cement (NHA-GIC) and Nano-hydroxyapatite-modified resin-modified glass ionomer cement (NHA-RMGIC) with conventional glass ionomer (CGIC) and resin-modified glass ionomer (RMGIC) in the treatment of caries class $V$ cavities. Sixty patients with at least two cervical caries lesions participated in this study. A total of 120 class $V$ cavities were prepared and then restored using different restorative materials. Restorations were clinically evaluated according to modified United States Public Health Service criteria at baseline and after 3, 6 and 9 months.

Results: There was no statistically significant difference in the clinical performance of the different restorative materials at any of the follow-up periods. However, throughout the study period there was a statistically significant change in the color match, surface texture and marginal integrity in NHA-GIC. A statistically significant change in the surface texture and marginal integrity was found in GIC. On the other hand, there was only a statistically significant change in surface texture in NHA-RMGIC.
\end{abstract}

Conclusions: All tested restorative materials, control (CGIC and RMGIC) as well as experimental (NHA-GIC and NHARMGIC), exhibited comparable clinical performance after 9 months follow-up.

Keywords: Glass ionomer, Nano-hydroxyapatite, Class V, Resin-modified glass ionomer, Modified USPHS criteria

\section{Background}

Cavities affecting the cervical regions of teeth are a common clinical finding. They might require restoration if associated with caries, to improve appearance, alleviate

\footnotetext{
*Correspondence: smnagi@gmail.com

${ }^{1}$ Restorative and Dental Materials Department, Oral and Dental Research Institute, National Research Centre, 33 El Bohouth st. (former El Tahrir st.), P.O. 12622, Dokki, Cairo, Egypt

Full list of author information is available at the end of the article
}

sensitivity or prevent enlargement of the lesion (Stewardson et al. 2012). Class V restorations represent a challenging situation in each step in the restorative procedure, including proper isolation, adhesion, contouring, finishing and polishing. Moreover, the cervical margin is mostly located in cementum or dentin which makes it more susceptible to microleakage, causing cavosurface stains, post-operative sensitivity, and recurrent caries (Perez 2010). 
A variety of tooth-colored restorative materials and adhesive agents are now suggested for the restoration of class V cavities. Either resin composite (RC) or glass ionomer cements (GICs) are recommended to restore these lesions. However, several drawbacks have been reported when resin composite is used to restore this type of cervical lesion, such as polymerization shrinkage, incomplete marginal sealing and resin-tooth interface degradation over time (Folwaczny et al. 2001; Boing et al. 2018).

Conventional glass ionomer and resin-modified glass ionomer have been advocated for restorations of class $\mathrm{V}$ restorations, especially in patients with high caries risk. A number of clinical trials have assessed the performance of GICs for restoring cervical lesions and these trials have demonstrated acceptable clinical results (Mahn et al. 2015; Priyadarshini et al. 2017). This might be related to the unique properties of GICs, such as chemical bonding to enamel and dentin, good sealing to cavity walls, caries-inhibition effect, remineralization potential due to the gradual release of fluoride ions for a long period, a coefficient of thermal expansion and elastic modules similar to those of the tooth structure, as well as minimal effect on the pulp tissue and easy handling properties (Singh et al. 2011).

Despite its various advantages, unfortunately GIC suffers from various shortcomings, such as poor physical properties, brittleness, low fracture toughness, inferior mechanical properties, high initial solubility, poor wear resistance, inadequate surface properties, moisture sensitivity and poor aesthetics when compared to resin composites (Khoroushi and Keshani 2013).

Recently, nanotechnology has rapidly expanded into all branches of dentistry as it offers significant alternative ways to solve scientific and medical questions and problems. Previous studies have suggested incorporation of nano-sized particles or nanoclusters, such as silver cermet, zinc, titanium dioxide, gold and zirconia as an attempt to improve the poor mechanical and physical properties of GIC and RMGIC (Khurshid et al. 2015; Najeeb et al. 2016). Although these modified reinforced materials exhibited high strength properties and reduced abrasion, they showed poor aesthetics, potential hazards, such as cytotoxicity that limits their use (Najeeb et al. 2016). Therefore, Nano-hydroxyapatite particles (NHA), with their chemistry being similar to that of mineralized bone and dental tissues, are considered an excellent candidate as filler material for both GICs and RMGICs (Kantharia et al. 2014).

Thus, it seems to be of value to study the effect of adding NHA on the clinical performance of CGI and RMGI restorations in class $\mathrm{V}$ cavities. This study was conducted to accept or reject the null hypotheses that:
There is no difference in the clinical performance of NHA-GI and NHA-RMGI in comparison to CGI and RMGI in class $\mathrm{V}$ cavities.

\section{Methods}

\section{Trial design and setting}

This double-blinded randomized, controlled, multicenter, split-mouth clinical trial with 1:1 allocation ratio was conducted at the dental clinic (DC) of the National Research Centre (NRC), Cairo, Egypt, and the restorative dental clinic at the Faculty of Oral and Dental Medicine, Girl's branch, Al-Azhar University, Cairo, Egypt. The experimental design followed the CONSORT 2010 guidelines (Consolidated Standards of Reporting Trial) (Table 1).

\section{Trial registration and ethical approval}

The trial was registered in the Pan African Clinical Trial Registry (PACTR) (www.pactr.org) under the identification number (PACTR201908519911054). The ethical approval was obtained from the Ethical Research Committee-National Research Centre (NRC), Cairo, Egypt (Ref number: 16039) and from the Faculty of Dental Medicine, Girls branch, Al-Azhar University, Cairo, Egypt (approval code:OPDEN-108-1-i) after looking for rights, safety and dignity of the clinical trial. This study was conducted in accordance with the 1964 Declaration of Helsinki and its subsequent amendments.

\section{Sample size calculation}

The sample size estimation was calculated using a priori by $G^{*}$ power 3.1.2 software based on previous studies (Burgess et al. 2004). The minimum size of each group was calculated, using the following conditions: $\alpha$ (allowable type I error) 0.05 (5\%), $\beta$ (allowable type II error) 0.20 $(20 \%)$, and power of the study $(1-\beta)=80 \%$. Thus, in order to detect a difference of $20 \%$, a minimum sample size of 25 teeth per group was needed. Considering 5 dropouts, the final restorations were placed in thirty teeth per

Table 1 Study design

\begin{tabular}{ll}
\hline Study type & Interventional (Clinical Trial) \\
\hline Estimated enrollment & 60 participants \\
Allocation: & Randomized \\
Intervention model & Parallel Assignment \\
Blindness & Double (Participant, Outcomes Assessor) \\
Primary purpose & Treatment of class V cavities \\
Study start date & June 2017 \\
Completion date & May 2019 \\
\hline
\end{tabular}


group which was obtained from 60 participants. Each participant received two restorations of class $\mathrm{V}$ lesions, totaling 120 dental restorations.

\section{Eligibility criteria}

Eligibility criteria for patients: Thirty participants with ages ranging from 25 to 45 years were selected to fulfill the following inclusion and exclusion criteria (Fagundes et al. 2014). The inclusion criteria for patients were: (a) ability to read and sign the informed consent form, (b) willingness to participate, (c) have no medical or behavioral problems preventing patients from attending recall treatments, and (d) moderate and high caries risk index. The exclusion criteria were: (a) rampant uncontrolled caries, (b) parafunctional habit, or bruxism (c) pregnant or breastfeeding, (d) heavy smoking, (e) evidence of xerostomia, and (f) presence of abnormal oral soft tissue.

Eligibility criteria for teeth: The inclusion criteria for teeth were: (a) presence of contra-lateral matched pair of cavitied buccal cervical carious lesion, (b) small to medium size cavities that extended into dentin, while maintaining natural tooth contour, (c) absence of tooth mobility, tenderness, extensive carious lesions, severe pain or pre-operative sensitivity, and (d) easily accessible gingival margins. The exclusion criteria were: (a) periapical pathology, internal or external resorption, (b) questionable pulp vitality or root canal therapy, (c) pulp capped, (d) periodontal pocket and bleeding on probing, (e) presence of cracks.

\section{Participant recruitment}

The patients were selected from the outpatient clinic of National Research Centre (NRC), Cairo, Egypt, and Faculty of Dental Medicine, Girl's branch, Al-Azhar University, Cairo, Egypt. Eligible patients who agreed to participate in this trial signed written informed consents.

Patient risk assessment using American Dental Association ${ }^{\circledR}$ (ADA) caries risk assessment form (Ages $>6$ ) was carried out for the all selected patients to be categorized into the medium and high risk category. Radiographical assessment was also performed to exclude patients with any sign of periapical pathosis.

\section{Randomization, allocation and blinding}

Each selected participant had two contra-lateral class V carious lesions and received the experimental restorative material (NHA-GIC or NHA-RMGIC) in one cavity and the corresponding control restorative material (CGIC or RMGIC) in the other cavity. Thus, a total of 120 restorations were placed in the 120 teeth of 60 patients.

The method used to generate the random allocation sequence of the participants and arch side was a computer-generated list of random numbers using
Microsoft ${ }^{\circledR}$ Excel program. Each participant occupied a sequence no (ID) from " 1 to 60 " and was randomly assigned to one of the two control restorative materials (either CGIC or RMGIC). Each participant was then given another randomized letter either "R" or "L," to determine which side was to be treated with the control material and eventually the other side was treated with the corresponding experimental material.

Generation of random allocation sequence was done by a person who was not involved in the clinical trial. Neither the participants nor the outcome assessor knew which tested restorative material was used, while the primary investigator was not blinded, thus resulting in a double-blind study.

\section{Procedure}

a. Preparation and characterization of Nanohydroxyapatite particles (NHA)

NHA were synthesized using the wet chemical precipitation method at the National Research Centre, Egypt. Synthesized NHA was then characterized by transmission electron microscopy (TEM), Fourier transform infrared spectroscopy (FTIR), X-ray diffraction (XRD), and elemental-dispersive X-ray (EDX) to study the powder purity, surface area and the particle size which affect their bioactivity, mechanical and biological properties.

Fourier transform infrared spectra were recorded for synthesized NHA by $\mathrm{KBr}$ disk technique using FTIR Spectrometer (Nexus 670 FTIR, USA). The NHA was analyzed in the range of $400-4000 \mathrm{~cm}^{-1}$ and at $4 \mathrm{~cm}^{-1}$ resolution to examine the chemical functional groups.

XRD analysis was done by using (Bruker D8 advance diffractometer, Germany) to determine different crystalline phases. The NHA was evaluated using $\mathrm{CU} \mathrm{K} \alpha_{1}$ radiation with a wavelength of $1.54 \mathrm{~A}^{\circ}$.

EDX was used to detect mineral element composition $(\mathrm{Ca} / \mathrm{P})$ of the synthesized NHA, by estimation of calcium (Ca) and phosphate (P) weight content (\%).

Moreover, Transmission electron microscopy (Philips $\mathrm{XL}, 30$; Japan) was used to evaluate the morphology and the particle size of synthesized NHA. The samples were prepared first by dispersing few particles of HA nanoparticles in distilled water, and then a carbon-coated copper grids 200 mesh (TED Pella, inc; USA) was dipped inside it. Particle size measurement was conducted using Clemex image analysis software.

b. Preparation and characterization of Nano-HA-modified glass ionomer cements 
Modified cements (NHA-GIC and NHA-RMGIC) were prepared by addition of NHA to the powder component of CGIC and RMGIC. Five percent by weight (5\% $\mathrm{w} / \mathrm{w}$ ) of CGIC or RMGIC powder were replaced by NHA and then mixed using a ball mill machine (LFJS, Hunan, China) with $200 \mathrm{rpm}$ for $30 \mathrm{~min}$ to produce a homogenous powder (Barandehfard et al. 2016; Poorzandpoush et al. 2017). The brand name, manufacturer and composition of the restorative materials are presented in Table 2.

Characterization of NHA-GIC and NHA-RMGIC was done using TEM (Philips XL, 30; Japan) to observe the distribution of NHA into CGIC and RMGIC powder.

c. Clinical procedure: Cavity preparation, material application, intervention and outcome

All participants' demographic data together with tooth numbers, types and arch distribution were recorded (Table 4). Each patient first underwent scaling and polishing procedures to clean the tooth surfaces.

The 120 cavities were prepared on 88 maxillary anterior teeth and 32 mandibular teeth. Appropriate local dental anesthesia (Mepecaine-L) $1 \mathrm{mg}$ had been injected preoperatively unless declined by the patient. Treated teeth were isolated with rubber dam (OptraDam ${ }^{\circledR}$ Plus) (Ivoclar Vivadent, size S \& M AG; USA) and saliva ejector.
A conservative class $\mathrm{V}$ cavity was prepared on the buccal surface of each tooth with a \#330 carbide bur (FG, Dentsply Midwest ${ }^{\circledR}$ ) fixed to a high-speed handpiece with water coolant system. Cavity preparation was limited to the removal of caries, and the exact cavity form and size were obtained after caries removal. Each bur was discarded after 5 preparations (Nassar et al. 2014).

After cavity preparation, the dentin was conditioned for $10 \mathrm{~s}$ with Ketac ${ }^{\mathrm{TM}}$ Conditioner, washed and gently dried with a cotton pellet. Control and experimental restorative materials were mixed according to manufacturer instructions and then packed into the prepared cavities on the contra-lateral side of each tooth.

NHA-GIC and CGIC restorations' finishing and polishing procedures were carried out immediately after initial setting of the restorative materials as recommended in the manufacturer's instructions for "single-visit treatment." On the other hand, NHA-RMGIC and RMGIC restorations were light-cured for $20 \mathrm{~s}$ prior to finishing and polishing. For all 120 restorations, excess material was removed with super-fine diamond burs under copious water coolant and restorations were polished with a SoF-Lex" abrasive disk. The restorations were finally coated with a thin layer of "EQUIA ${ }^{\circledR}$ Coat," and then light-cured for $20 \mathrm{~s}$. Patients were instructed to maintain

Table 2 Name, specifications, composition, manufacturer and batch numbers of the restorative materials

\begin{tabular}{|c|c|c|c|c|c|}
\hline Material & Specification & Composition & Manufacturer & Batch ne & Imbers \\
\hline $\begin{array}{l}\text { Fuji Il, GC Gold } \\
\text { Label } 2 \\
\text { (GIC) }\end{array}$ & $\begin{array}{l}\text { Conventional } \\
\text { Glass lonomer } \\
\text { Cement } \\
(\mathrm{CGIC})\end{array}$ & $\begin{array}{l}\text { Powder }(10 \mathrm{~g}) \\
\text { Acid soluble "calciumfluoroalumino-silicate } \\
\text { glass" } \\
\text { Liquid } 7 \mathrm{~g}(5.6 \mathrm{ml}) \\
\text { Polyacrylic acid (40\%), Tartaric acid (5-15\%), } \\
\text { Maleic acid, Itaconic acid and distilled water }\end{array}$ & $\begin{array}{l}\text { GC } \\
\text { Corporation, Tokyo, Japan }\end{array}$ & $\begin{array}{l}\text { Powder } \\
\text { Liquid: }\end{array}$ & $\begin{array}{l}1603011 \\
1603021\end{array}$ \\
\hline NHA-CGIC & Experimental GIC & $\begin{array}{l}\text { GGIC incorporated with 5\% Nano-HAp in the } \\
\text { powder component }\end{array}$ & & & \\
\hline $\begin{array}{l}\text { Fuji IILC, } \\
\text { improved, GC } \\
\text { (RMGIC) }\end{array}$ & $\begin{array}{l}\text { Resin-Modified Glass lono- } \\
\text { mer Cement (RMGIC) }\end{array}$ & $\begin{array}{l}\text { Powder ( } 15 \mathrm{~g} \text { ) } \\
\text { same composition of chemically cured GIC } \\
\text { powder "100\% of "calciumfluoroalumino- } \\
\text { silicate glass" } \\
\text { Liquid } 8 \mathrm{~g}(6.8 \mathrm{ml}) \\
\text { polyacrylic acid }(20-22 \%), 2 \mathrm{HEMA}^{*}(35- \\
40 \%), 2,2,4 \text { TEGDMA**, }(4-6 \%), \mathrm{TMHMDC}^{* * *} \\
(5-7 \%), \text { Camphorquinone }(10 \%) \text { and distilled } \\
\text { water }\end{array}$ & $\begin{array}{l}\text { GC } \\
\text { Corporation, Tokyo, Japan }\end{array}$ & $\begin{array}{l}\text { Powder } \\
\text { Liquid: }\end{array}$ & $\begin{array}{l}1601051 \\
1601061\end{array}$ \\
\hline NHA-RMGIC & Experimental RMGIC & $\begin{array}{l}\text { RMGIC incorporated with 5\% Nano-HAp in } \\
\text { the powder component }\end{array}$ & & & \\
\hline $\begin{array}{l}\text { Ketac }^{\mathrm{TM}} \\
\text { conditioner }^{-}\end{array}$ & $\begin{array}{l}\text { Dentin conditioner } \\
\text { (pretreatment) }\end{array}$ & $\begin{array}{l}\text { Liquid (IOml) } \\
\text { Polyacrylic acid (10\%) }\end{array}$ & 3M ESPE, Deutschland, German & 668400 & \\
\hline EQUIA $^{\circledR}$ Coat & Light-cure self-adhesive coat & $\begin{array}{l}\text { Liquid }(6 \mathrm{ml}) \\
50 \% \mathrm{MMA}^{* * * *}, 0.09 \% \text { camphorquinone }\end{array}$ & $\begin{array}{l}\text { GC } \\
\text { Corporation, Tokyo, Japan }\end{array}$ & 104251 & \\
\hline $\begin{array}{l}\text { Hydroxyapatite } \\
\text { nanoparticles } \\
\text { (NHA) }\end{array}$ & Additive reinforcing powder & $\mathrm{Ca} a_{5}(\mathrm{OH})\left(\mathrm{PO}_{4}\right)_{3}$ & National Research Centre (NRC) & - & \\
\hline
\end{tabular}

${ }^{*} H E M A$ hydroxyethyl-methacrylate, ${ }^{* *} T E G D M A$ triethylene-glycol dimethacrylate, ${ }^{* * *} T M H M D C$ trimethyl-hexamethylenedicarbonate, ${ }^{* * * *} M M A$ methyl-methacrylate 
optimum oral hygiene measures and the importance of periodic follow-up and recall were highlighted.

The primary outcome measure was evaluation of the clinical performance of the tested restorative materials using modified (USPHS) criteria (Kharma et al. 2018) (Table 3). All criteria were evaluated at regular visits; at baseline (immediately) and after 3, 6 and 9 months. All the restorations were evaluated for the outcome by a single experienced, calibrated independent examiner who was blinded to the objectives of this study and tooth allocation. The restorations were evaluated visually by using mirror and probe under good operating light.

All data about patient's enrollment, intervention, follow-up and data analysis are shown in CONSORT flow diagram 2010, Fig. 1.

\section{Statistical analysis}

Qualitative data were presented as frequencies and percentages. Wilcoxon signed-rank test was used to compare each group and its contra-lateral side. Friedman's test was used to study the changes with time within each group. Chi-square test or Fisher's Exact test (when applicable) were used to compare the groups. The significance level was set at $P \leq 0.05$. Statistical analysis was performed with IBM ${ }^{\circledR}$ SPSS $^{\circledR}$ Statistics for Windows, Version 23.0. Armonk, NY: IBM Corp.

\section{Results}

a. Results of Synthesized NHA characterization

1. Fourier transform infrared spectroscopy (FTIR) analysis

Figure 2 represents the FTIR spectrum of the prepared NHA by the wet chemical precipitation method. The figure shows all the characteristic bands for hydroxyapatite; the asymmetric stretching $\left(\mathrm{v}_{3}\right)$ and bending $\left(\mathrm{v}_{4}\right)$ modes of $\mathrm{PO}_{4}{ }^{-3}$ ion were detected at around $1067.9,610.1$ and $536.7 \mathrm{~cm}^{-1}$, respectively. The symmetrical stretching modes $\left(\mathrm{v}_{1}\right)$ and $\left(\mathrm{v}_{2}\right)$ of $\mathrm{PO}^{-3}$ ion were also found at around 970.4 and $430.4 \mathrm{~cm}^{-1}$, respectively. The liberation and stretching mode of the $\mathrm{OH}-$ were detected at around 3471 and $1657 \mathrm{~cm}^{-1}$, respectively. The stretching vibrations, ascribed to $\mathrm{CO}_{3}{ }^{2-}$, were also present at around 1400.1 and $816 \mathrm{~cm}^{-1}$. The bands at 3471.3 and $1657.5 \mathrm{~cm}^{-1}$ correspond to adsorbed $\mathrm{H}_{2} \mathrm{O}$.

\section{X-ray diffraction (XRD) analysis}

Figure 3 represents the XRD analysis of the prepared NHA. The characteristic peaks of NHA were clearly detected. Also, it was observed that most of the peaks fit well with hexagonal hydroxyapatite phase. The phase analysis of crystalline NHA shown was carried out with

Table 3 Primary outcome, measuring devices and measuring units for in vivo study using modified (USBHS) criteria

\begin{tabular}{|c|c|c|c|c|}
\hline \multirow{2}{*}{$\begin{array}{l}\text { Primary outcome } \\
\text { Retention }\end{array}$} & \multirow{2}{*}{$\begin{array}{l}\text { Measuring devices } \\
\text { Visual inspection with mirror at } \\
18 \text { inches }\end{array}$} & \multicolumn{3}{|l|}{ Measuring units } \\
\hline & & $\begin{array}{l}\text { Complete retention } \\
\text { Mobilization of the restoration } \\
\text { Loss of the restoration }\end{array}$ & $\begin{array}{l}\text { Alpha }(A) \\
\text { Bravo (B) } \\
\text { Charlie (C) }\end{array}$ & \\
\hline Color match & $\begin{array}{l}\text { Visual inspection with mirror at } \\
18 \text { inches }\end{array}$ & \multicolumn{2}{|c|}{$\begin{array}{l}\text { Perfectly matched color shade } \\
\text { Unperfected color match. Unacceptable color match }\end{array}$} & $\begin{array}{l}\text { Alpha (A) } \\
\text { Bravo (B) } \\
\text { Charlie (C) }\end{array}$ \\
\hline Marginal integrity & $\begin{array}{l}\text { Visual inspection with explorer } \\
\text { and mirror, if needed }\end{array}$ & \multicolumn{2}{|c|}{$\begin{array}{l}\text { Absence of discrepancy at probing } \\
\text { Presence of discrepancy at probing without dentin exposure } \\
\text { Probe penetrates in the discrepancy at probing with dentin expo- } \\
\text { sure }\end{array}$} & $\begin{array}{l}\text { Alpha (A) } \\
\text { Bravo (B) } \\
\text { Charlie (C) }\end{array}$ \\
\hline Marginal discoloration & $\begin{array}{l}\text { Visual inspection with mirror at } \\
18 \text { inches }\end{array}$ & \multicolumn{2}{|c|}{$\begin{array}{l}\text { Absence of marginal discoloration } \\
\text { Presence of marginal discoloration limited and not extended } \\
\text { Evident marginal discoloration penetrated toward the pulp chamber }\end{array}$} & $\begin{array}{l}\text { Alpha }(A) \\
\text { Bravo (B) } \\
\text { Charlie }(C)\end{array}$ \\
\hline Surface texture & $\begin{array}{l}\text { Visual inspection with explorer } \\
\text { and mirror, if needed }\end{array}$ & \multicolumn{2}{|l|}{$\begin{array}{l}\text { Surface is not rough } \\
\text { Surface is slightly rough } \\
\text { Surface is highly rough }\end{array}$} & $\begin{array}{l}\text { Alpha }(A) \\
\text { Bravo (B) } \\
\text { Charlie }(C)\end{array}$ \\
\hline Surface staining & $\begin{array}{l}\text { Visual inspection with explorer } \\
\text { and mirror, if needed }\end{array}$ & \multicolumn{2}{|l|}{$\begin{array}{l}\text { Surface is not staining } \\
\text { Surface is slightly staining } \\
\text { Surface is highly staining }\end{array}$} & $\begin{array}{l}\text { Alpha (A) } \\
\text { Bravo (B) } \\
\text { Charlie (C) }\end{array}$ \\
\hline Postoperative sensitivity & Ask the patient. "Questionnaire" & \multicolumn{2}{|c|}{$\begin{array}{l}\text { Absence of hypersensitivity } \\
\text { Mild hypersensitivity } \\
\text { Presence of strong and intolerable hypersensitivity }\end{array}$} & $\begin{array}{l}\text { Alpha }(A) \\
\text { Bravo (B) } \\
\text { Charlie (C) }\end{array}$ \\
\hline Secondary caries & $\begin{array}{l}\text { Visual inspection with explorer } \\
\text { and mirror, if needed }\end{array}$ & \multicolumn{2}{|c|}{$\begin{array}{l}\text { No evidence of caries } \\
\text { Evidence of caries along the margin of the restoration }\end{array}$} & $\begin{array}{l}\text { Alpha }(A) \\
\text { Charlie }(C)\end{array}$ \\
\hline
\end{tabular}




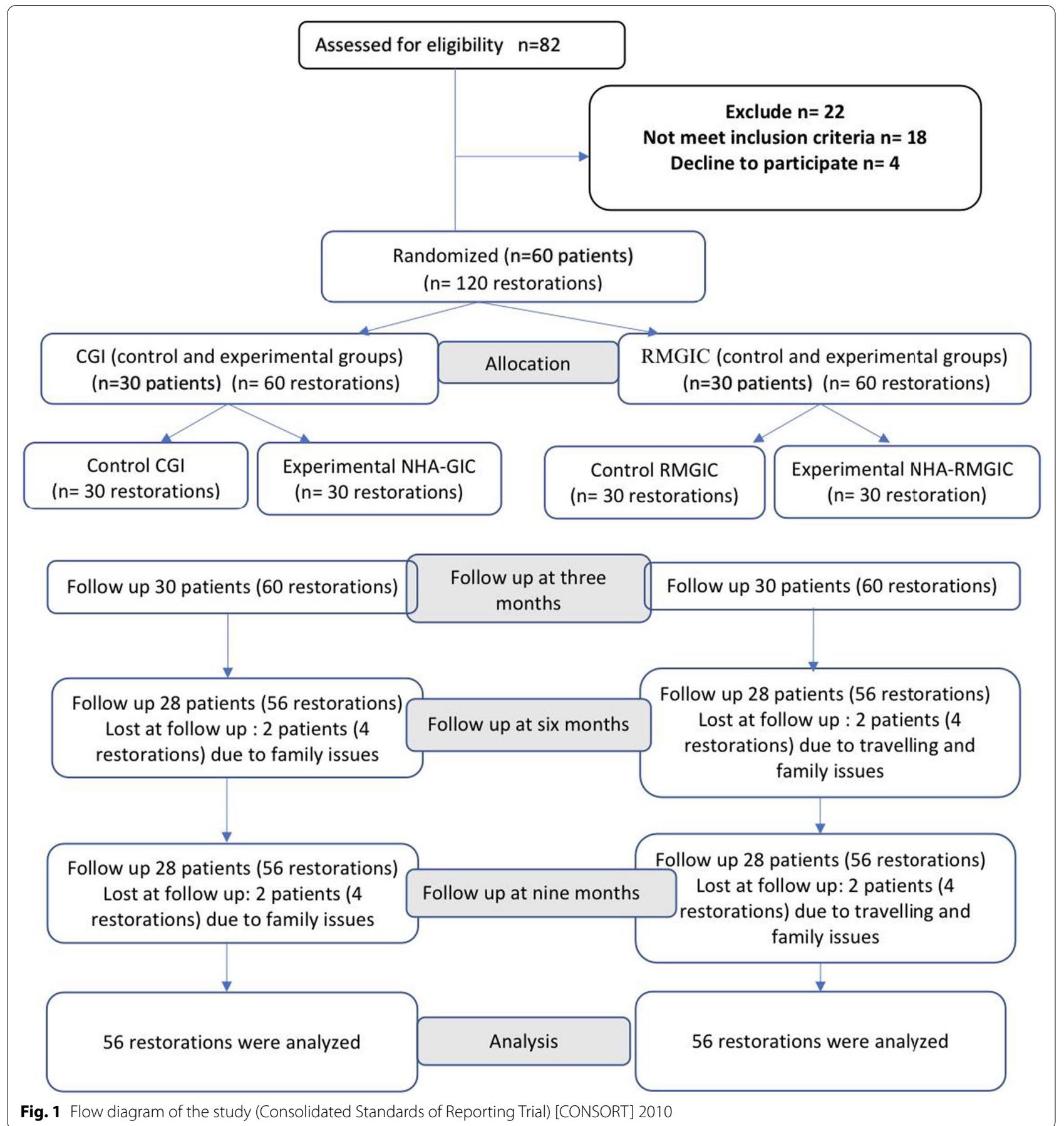

the help of Joint Committee on Powder Diffraction Standards (JCPDS) data card no. 09-0432. The grain size D of NHA was calculated.

3. Energy-dispersive X-ray (EDX)
Figure 4 represents the elemental analysis of NHA, which indicates the elemental compositions of the material. The EDX spectra clearly showed that the prepared NHA constitutes mainly calcium and phosphate groups, while the weight percentages of calcium $(\mathrm{Ca})$, 


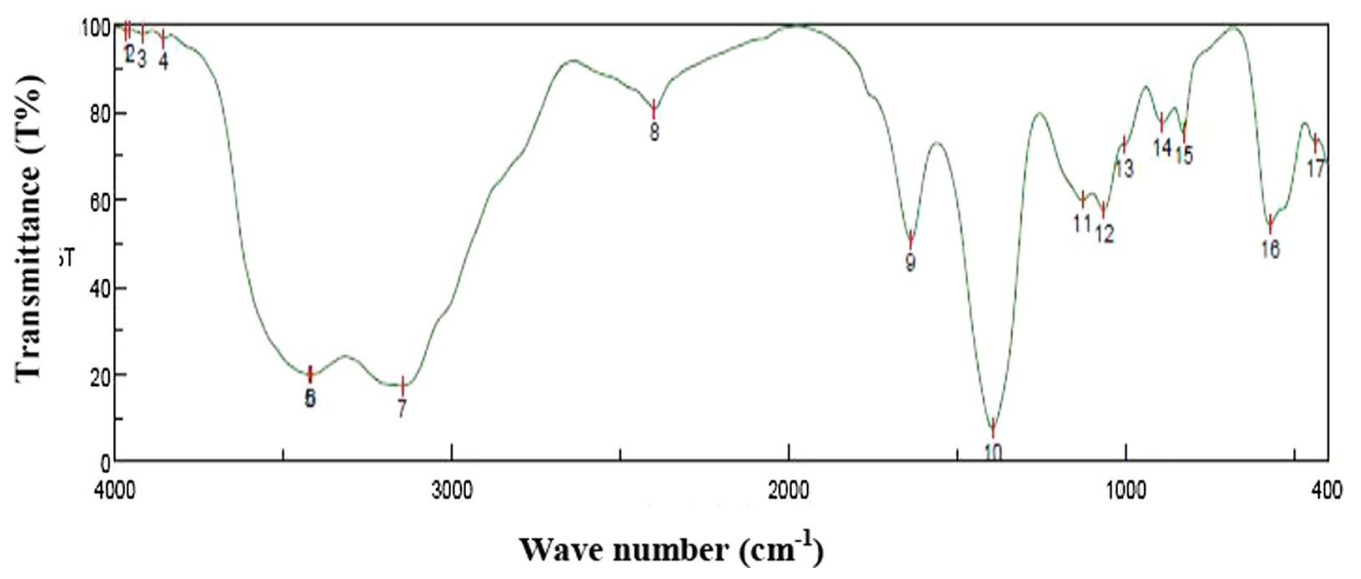

Fig. 2 FTIR spectrum of the prepared NHA

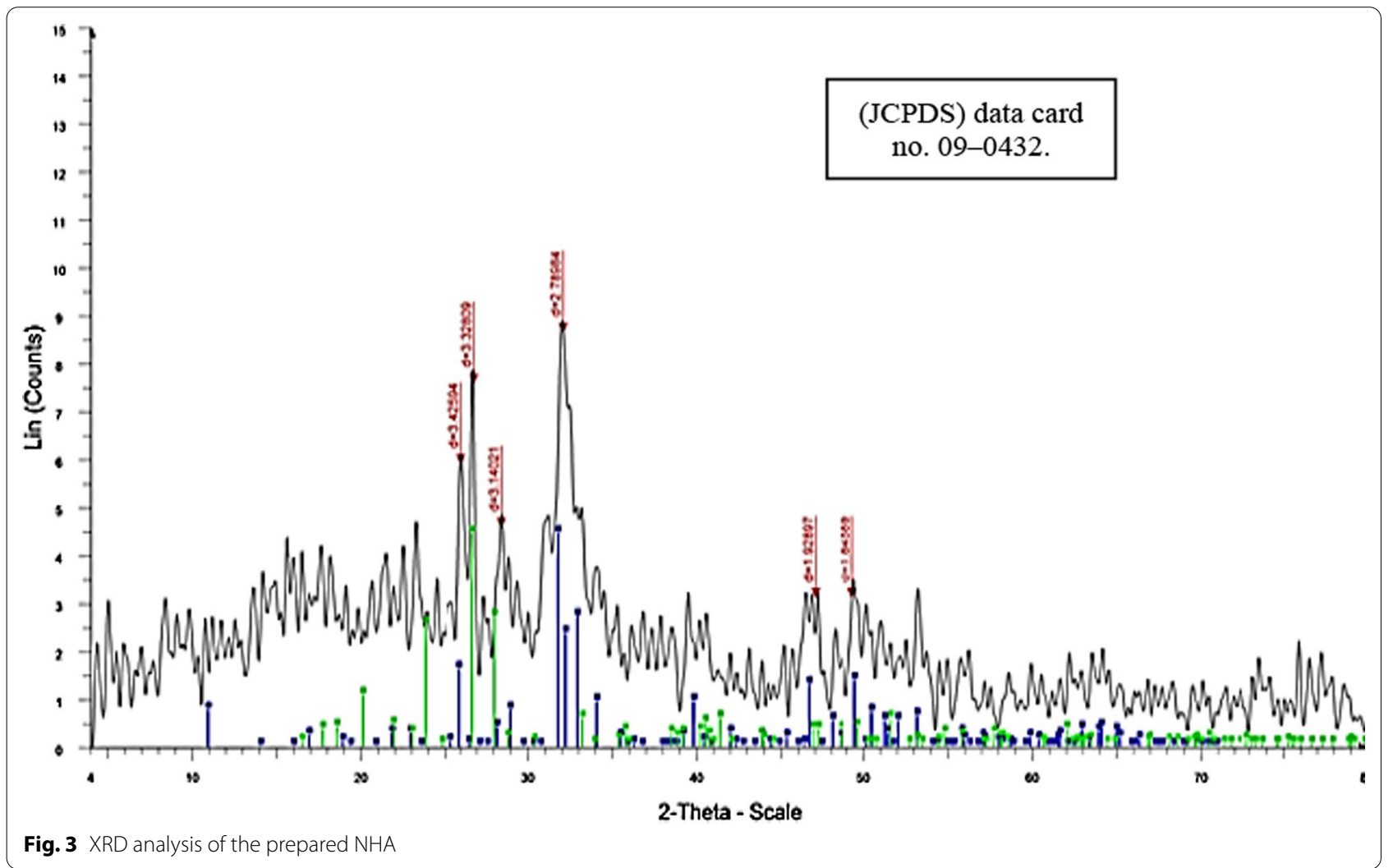

phosphorous $(\mathrm{P})$ and oxygen $(\mathrm{O})$ element were found to be $31.26 \%, 21.92 \%$ and $46.82 \%$, respectively.

4. Transmission electron microscope (TEM) observation
Figure 5 represents a transmission electron microscope (TEM) photomicrograph of the prepared NHA. The morphology of NHA appears in nanostructure form and uniform rod shape. The crystalline size of the prepared NHA was estimated from TEM micrographs by image analysis, which has an estimated crystalline 


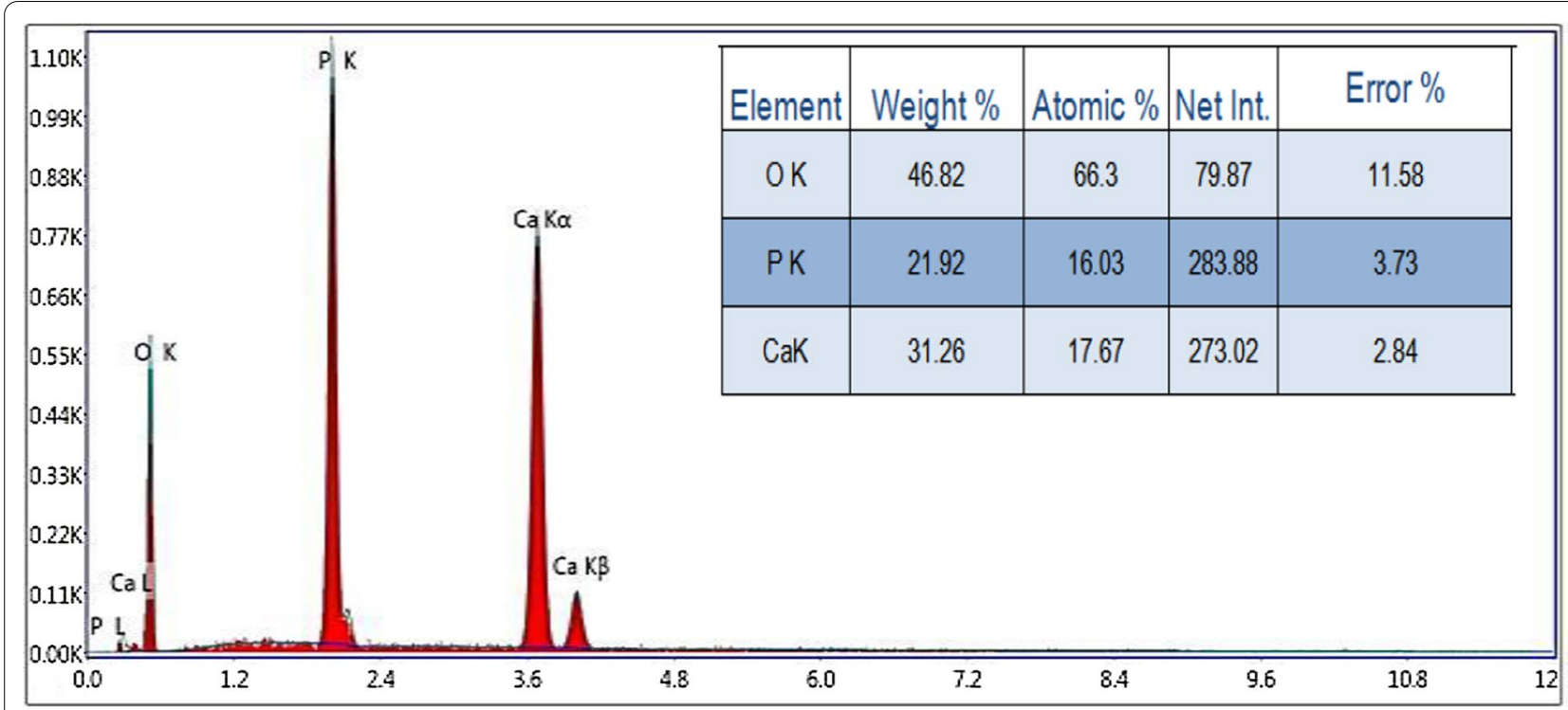

Lsec: 30.00 Cnts 0.000 keV Det: Octane Pro Det Reso

Fig. 4 EDX spectra of the prepared NHA

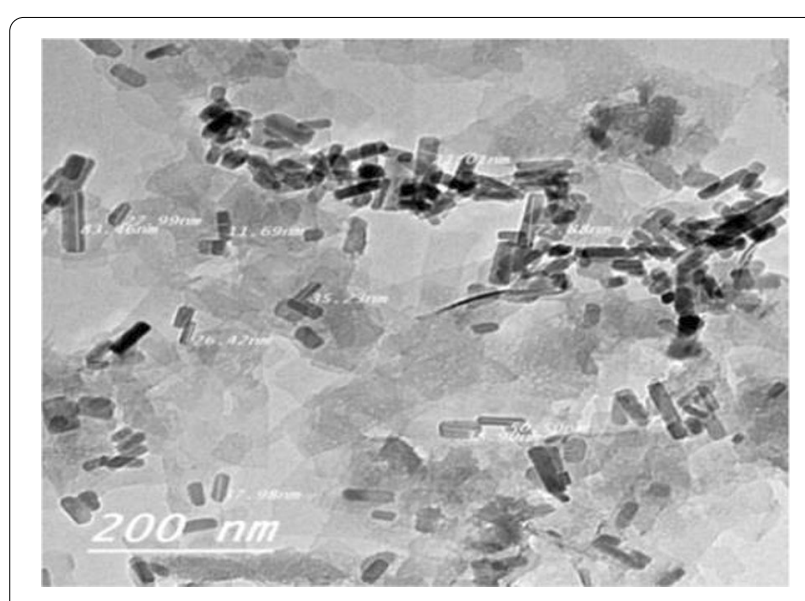

Fig. 5 TEM photomicrograph of the prepared NHA

size about $(20-80) \mathrm{nm}$ in length and $(10-25) \mathrm{nm}$ in width.

b. Results of characterization of Nano-HA-modified glass ionomer cements

Figures $6 \mathrm{a}, \mathrm{b}$ and $7 \mathrm{a}$, b represent TEM photomicrographs of the prepared NHA-GIC and NHA-RMGIC powder, respectively. The rod-shaped NHA particles were easily detected distributed inside the CGIC and RMGIC powder. c. Results of the in vivo study

Table 4 shows the frequencies, percentages (\%) and results of the Chi-square test for comparisons of demographic data of the two main groups (CGIC, NHA-GIC) and (RMGIC, NHA-RMGIC). The table demonstrated that there was no statistically significant difference between the two groups as regards age distribution, gender distributions, marital status, arch and tooth types at $P$ value $0.705,0.713,0.169,0.243$ and 0.480 , respectively.

Table 5 presents data for retention, color match, surface texture, surface staining, marginal discoloration, marginal integrity, secondary caries, and post-operative sensitivity at all evaluation periods. The total number of restorations assessed at each time period is given in percent, and the numbers in parenthesis indicate the total number of restorations classified as Alpha $(\mathrm{A})+$ the total number of restorations classified as Bravo (B) in that evaluation period.

At baseline as well as after 3 months, all restorations in the four groups showed Alpha score for all evaluation criteria except for color match, surface texture, and postoperative sensitivity.

After 6 as well as 9 months, two patients had dropped out $(6.7 \%)$ in each group. There was no statistically significant difference between the four groups for any of the evaluated criteria at each follow-up period. 

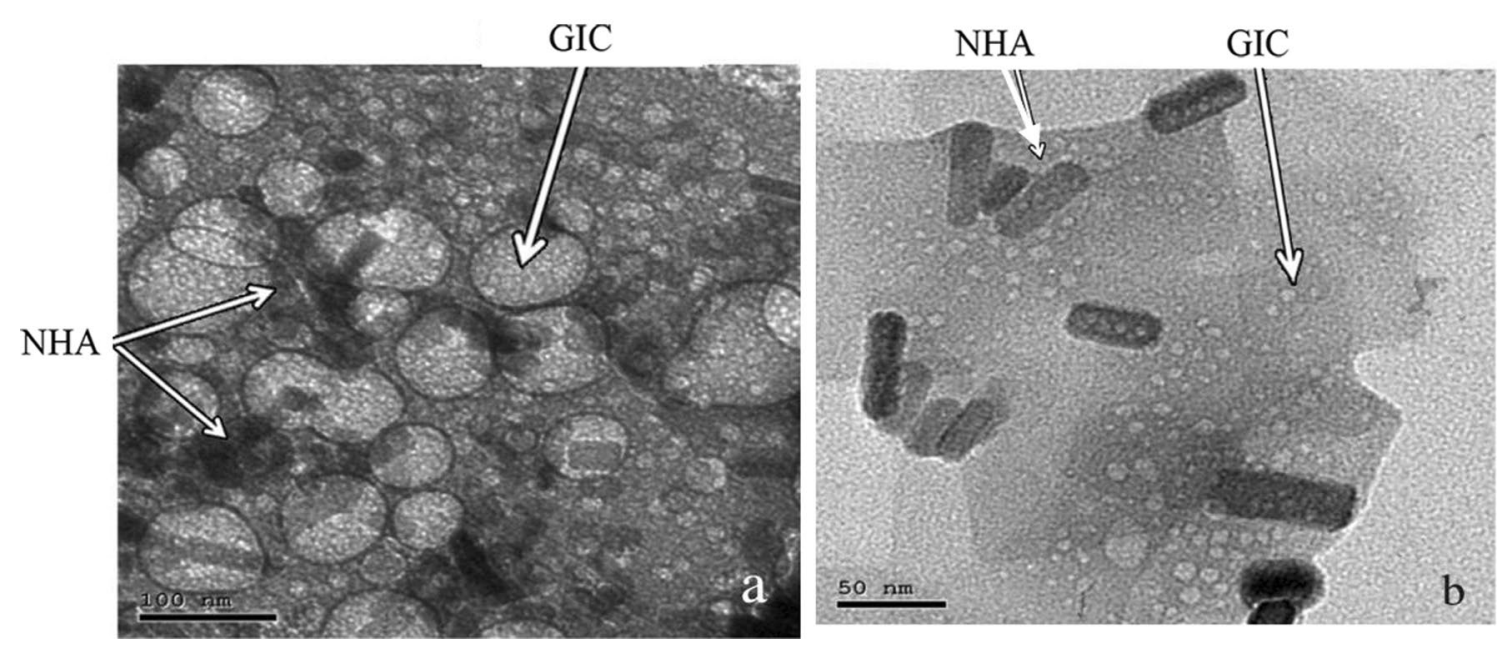

Fig. 6 a, b TEM photomicrographs of the prepared NHA-GIC powder


Fig. 7 a, b TEM photomicrographs of the prepared NHA-RMGIC powder

Analysis of the changes with time within each group, revealed that there was no statistically significant change in most of the tested criteria through the study period. The exceptions were as follows. In the NHA-GIC group, there was a statistically significant change in color match, surface texture, and marginal integrity through the study period. In the CGIC group there was a statistically significant change in surface texture and marginal integrity through the study period. In the RMGIC group there was a statistically significant change in color match and surface texture through the study period. Finally, in the NHA-RMGIC group there was only a statistically significant change in surface texture through the study period.
The overall cumulative survival rate was $100 \%$ and a survival plot cannot be drawn since all tested restorative materials either, "control or experimental," showed Alpha and Bravo scores which were considered as successful.

\section{Discussion}

This randomized clinical trial investigated the clinical performance of the modified, experimental cements (NHA-GIC and NHA-RMGIC) and compared the performance to their respective control cements (CGIC and RMGIC) in class $\mathrm{V}$ cavities at baseline (immediately) and after 3, 6 and 9 months using modified USPHS criteria (retention, color match, surface texture, surface staining, 
Table 4 Frequencies, percentages (\%) and results of the Chisquare test for comparison of demographic data of the two main groups

\begin{tabular}{|c|c|c|c|}
\hline & $\begin{array}{l}\text { CGIC } \\
\text { NHA-GIC } \\
(n=30) \text { patients }\end{array}$ & $\begin{array}{l}\text { RMGIC } \\
\text { NHA-RMGI } \\
(n=30) \text { patients }\end{array}$ & $P$ value \\
\hline Age & & & 0.705 \\
\hline $25-35 y$ & $12(40 \%)$ & $10(33.3 \%)$ & \\
\hline $35-45 y$ & 18 (60\%) & $20(66.7 \%)$ & \\
\hline Gender & & & 0.713 \\
\hline Male & $14(46.7)$ & $12(40 \%)$ & \\
\hline Female & $16(53.3)$ & $18(60 \%)$ & \\
\hline Marital status & & & 0.169 \\
\hline Single & $10(33.3 \%)$ & $2(6.7 \%)$ & \\
\hline Married & $20(66.7 \%)$ & $28(93.3 \%)$ & \\
\hline Arch & & & 0.243 \\
\hline Upper & 40 (66.7\%) & $48(80 \%)$ & \\
\hline Lower & $20(33.3 \%)$ & $12(20 \%)$ & \\
\hline Tooth type & & & 0.480 \\
\hline Central incisor & 16 (26.7\%) & $16(26.7 \%)$ & \\
\hline Lateral incisor & $16(26.7 \%)$ & $24(40 \%)$ & \\
\hline Canine & $28(46.7 \%)$ & $20(33.3 \%)$ & \\
\hline
\end{tabular}

*Significant at $P \leq 0.05$

marginal adaptation, marginal discoloration, recurrent caries and post-operative sensitivity).

At the 9 month recall, all restorations, irrespective of material, showed excellent retention [93.3\% (Alpha) rating], which confirms the results of previous studies (Loguercio et al. 2003; Franco et al. 2006; Jyothi et al. 2011; Fagundes et al. 2014). The high retention rate reported for both Fuji GC Gold Label 2 (CGIC) and Fuji II LC (RMGIC) might be related to their relatively good mechanical properties and better adhesion mechanism to dental tissue. The auto-adhesive capacity of GICs through the formation of ionic bonds between the carboxyl groups of polyalkenoic acid and hydroxyapatite in the tooth structure might have been responsible for higher retention rate of these materials (Shikumar et al. 2016). Moreover, the micro-mechanical interlocking of the polymer in RMGIC added another adhesion mechanism, which might participate in improving its retention rate (Jyothi et al. 2011). Another factor associated with the favorable retention performance of CGIC and RMGIC, was the fact that these materials have elastic modules close to that of tooth structure (Shikumar et al. 2016). This increases the strain capacity of the restorations and prevents their deformation under occlusal load, thus preserving the adhesion of the materials at the margins of the cavities (Abdalla et al. 1997). The fact that there was no significant difference between the experimental groups (NHA-GIC and NHA-RMGIC) and the control groups (CGIC and RMGIC) regarding the retention rates might be due to the similarity in general mechanical and physical properties between the control and the experimental cements.

The results of clinical performance regarding the color matching showed that there was no statistically significant difference between the four tested restorative materials during the study period. Nevertheless, there were statistically significant changes in the color matching criterion through the 9 months study period in the NHA-GIC and RMGIC groups. There was an increase in prevalence of Bravo scores and a decrease in prevalence of Alpha scores from 3 to 6 in NHA-GIC and RMGIC groups, as well as from 6 to 9 months in NHA-GIC. These results were in accordance with several previous clinical trials (Folwaczny et al. 2001; Sidhu 2010; Lee et al. 2010; Priyadarshini et al. 2017). The poor color match for both CGIC and RMGIC, control as well as experimental groups, could be related to the "chalking phenomenon" of glass ionomers which damages its appearance under dry conditions making the surface appear weak and opaque (Perdigão et al. 2012). Moreover, the presence of porosity and microcracks within the glass ionomer microstructure, might be another factor that affects the color stability of the tested cements. This allowed for the accumulation of oral fluid and stain adsorption and discoloration of the restoration (Priyadarshini et al. 2017). In addition, lack of color stability in GICs could be attributed to the polyacid content in the material, which could be explained by degradation of the metal polyacrylate salts. When GICs were exposed to acid attack (depending upon $\mathrm{pH}$ of the patient oral environment), $\mathrm{H}^{+}$ions diffuse into the glass ionomer component and replace the metal cations in the matrix. These cations later diffuse outwards and get released to the cement surface. Thus, the material might become rough with voids, and undissolved glass particles result in greater water and food colorant absorption (Cardoso et al. 2010). Moreover, RMGIC "Fuji II LC, improved" undergoes color change during polymerization of the resin components as the acid-base reaction is retarded. This delayed acid-base reaction in addition to water sorption by the resin components within RMGIC might result in postpolymerization color change (Adusumilli et al. 2016). Furthermore, the hydrophilic monomers, incomplete polymerization, residual HEMA molecules after lightcuring, physical adsorption and desiccation might also affect the color stability of RMGIC and increase its potential body discoloration and surface staining (Cardoso et al. 2010; Hussainy et al. 2018).

In contrast to these results Hussainy et al. (2018) observed close color matching and high color stability 
Table 5 Descriptive statistics and results of Fisher's Exact test for comparison between the four groups

\begin{tabular}{|c|c|c|c|c|c|c|c|}
\hline \multirow[t]{2}{*}{ Category } & \multirow[t]{2}{*}{ Material } & \multirow{2}{*}{$\begin{array}{l}\text { Baseline } \\
\%(A+B)\end{array}$} & \multirow{2}{*}{$\frac{3 \text { months }}{\%(A+B)}$} & \multirow{2}{*}{$\begin{array}{l}6 \text { months } \\
\%(A+B)\end{array}$} & \multirow{2}{*}{$\begin{array}{l}9 \text { months } \\
\%(A+B)\end{array}$} & \multirow[b]{2}{*}{$P$ value } & \multirow[b]{2}{*}{ Effect size (W) } \\
\hline & & & & & & & \\
\hline \multirow[t]{6}{*}{ Retention } & CGIC & $100 \%(100+0)$ & $100 \%(100+0)$ & $93.3 \%(93.3+0)$ & $93.3 \%(93.3+0)$ & 0.392 & 0.067 \\
\hline & NHA-GIC & $100 \%(100+0)$ & $100 \%(100+0)$ & $93.3 \%(93.3+0)$ & $93.3 \%(93.3+0)$ & 0.392 & 0.067 \\
\hline & RMGIC & $100 \%(100+0)$ & $100 \%(100+0)$ & $93.3 \%(93.3+0)$ & $93.3 \%(93.3+0)$ & 0.392 & 0.067 \\
\hline & NHA-RMGIC & $100 \%(100+0)$ & $100 \%(100+0)$ & $93.3 \%(93.3+0)$ & $93.3 \%(93.3+0)$ & 0.392 & 0.067 \\
\hline & & $P=N C^{+}$ & $P=N C^{\dagger}$ & $P=1.000$ & $P=1.000$ & & \\
\hline & & Effect size $=\mathbf{N} \boldsymbol{C}^{+}$ & Effect size $=\mathbf{N} \boldsymbol{C}^{+}$ & Effect size $=0.0000$ & Effect size $=0.0000$ & & \\
\hline \multirow[t]{6}{*}{ Color match } & CGIC & $100 \%(80+20)$ & $100 \%(80+20)$ & $93.3 \%(73.3+20)$ & $93.3 \%(66.7+26.7)$ & 0.061 & 0.164 \\
\hline & NHA-GIC & $100 \%(86.7+13.3)$ & $100 \%(80+20)$ & $93.3 \%(66.7+26.7)$ & $93.3 \%(60+33.3)$ & $0.010 *$ & 0.252 \\
\hline & RMGIC & $100 \%(80+20)$ & $100 \%(80+20)$ & $93.3 \%(66.7+26.7)$ & $93.3 \%(66.7+26.7)$ & $0.029^{*}$ & 0.200 \\
\hline & NHA-RMGIC & $100 \%(73.3+26.7)$ & $100 \%(73.3+26.7)$ & $93.3 \%(66.7+26.7)$ & $93.3 \%(60+33.3)$ & 0.061 & 0.164 \\
\hline & & $P=0.969$ & $P=1.000$ & $P=1.000$ & $P=1.000$ & & \\
\hline & & Effect size $=0.118$ & Effect size $=0.070$ & Effect size $=0.048$ & Effect size $=0.052$ & & \\
\hline \multirow{6}{*}{$\begin{array}{l}\text { Surface } \\
\text { texture }\end{array}$} & CGIC & $100 \%(100+0)$ & $100 \%(100+0)$ & $93.3 \%(80+13.3)$ & $93.3 \%(66.7+26.7)$ & $0.007^{*}$ & 0.267 \\
\hline & NHA-GIC & $100 \%(100+0)$ & $100 \%(93.3+6.7)$ & $93.3 \%(73.3+20)$ & $93.3 \%(66.7+26.7)$ & $0.005^{*}$ & 0.285 \\
\hline & RMGIC & $100 \%(100+0)$ & $100 \%(100+0)$ & $93.3 \%(73.3+20)$ & $93.3 \%(60+33.3)$ & $0.002^{*}$ & 0.327 \\
\hline & NHA-RMGIC & $100 \%(100+0)$ & $100 \%(100+0)$ & $93.3 \%(66.7+26.7)$ & $93.3 \%(53.3+40)$ & $0.001^{*}$ & 0.390 \\
\hline & & $P=N C^{\dagger}$ & $P=1.000$ & $P=0.997$ & $P=0.992$ & & \\
\hline & & Effect size $=\mathbf{N} \boldsymbol{C}^{\dagger}$ & Effect size $=0.225$ & Effect size $=0.084$ & Effect size $=0.085$ & & \\
\hline \multirow{6}{*}{$\begin{array}{l}\text { Surface stain- } \\
\text { ing }\end{array}$} & CGIC & $100 \%(100+0)$ & $100 \%(100+0)$ & $93.3 \%(86.7+6.7)$ & $93.3 \%(86.7+6.7)$ & 0.112 & 0.133 \\
\hline & $N H A-G I C$ & $100 \%(100+0)$ & $100 \%(100+0)$ & $93.3 \%(93.3+0)$ & $93.3 \%(80+13.3)$ & 0.066 & 0.160 \\
\hline & RMGIC & $100 \%(100+0)$ & $100 \%(100+0)$ & $93.3 \%(93.3+0)$ & $93.3 \%(93.3+0)$ & 0.392 & 0.067 \\
\hline & NHA-RMGIC & $100 \%(100+0)$ & $100 \%(100+0)$ & $93.3 \%(86.7+6.7)$ & $93.3 \%(86.7+6.7)$ & 0.112 & 0.133 \\
\hline & & $P=N C^{+}$ & $P=N C^{+}$ & $P=0.997$ & $P=0.992$ & & \\
\hline & & Effect size $=\boldsymbol{N} \boldsymbol{C}^{+}$ & Effect size $=\mathbf{N} \boldsymbol{C}^{\dagger}$ & Effect size $=0.084$ & Effect size $=0.085$ & & \\
\hline \multirow{6}{*}{$\begin{array}{l}\text { Marginal } \\
\text { discoloration }\end{array}$} & CGIC & $100 \%(100+0)$ & $100 \%(100+0)$ & $93.3 \%(86.7+6.7)$ & $93.3 \%(86.7+6.7)$ & 0.112 & 0.133 \\
\hline & $N H A-G I C$ & $100 \%(100+0)$ & $100 \%(100+0)$ & $93.3 \%(93.3+0)$ & $93.3 \%(80+13.3)$ & 0.066 & 0.160 \\
\hline & RMGIC & $100 \%(100+0)$ & $100 \%(100+0)$ & $93.3 \%(93.3+0)$ & $93.3 \%(93.3+0)$ & 0.392 & 0.067 \\
\hline & NHA-RMGIC & $100 \%(100+0)$ & $100 \%(100+0)$ & $93.3 \%(93.3+0)$ & $93.3 \%(86.7+6.7)$ & 0.194 & 0.105 \\
\hline & & $P=N C^{+}$ & $P=N C^{\dagger}$ & $P=1.000$ & $P=0.989$ & & \\
\hline & & Effect size $=\boldsymbol{N} \boldsymbol{C}^{+}$ & Effect size $=\mathbf{N} \boldsymbol{C}^{\dagger}$ & Effect size $=0.160$ & Effect size $=0.134$ & & \\
\hline \multirow{6}{*}{$\begin{array}{l}\text { Marginal } \\
\text { integrity } \\
\text { (adaptation) }\end{array}$} & $C G / C$ & $100 \%(100+0)$ & $100 \%(100+0)$ & $93.3 \%(80+13.3)$ & $93.3 \%(66.7+26.7)$ & $0.007^{*}$ & 0.267 \\
\hline & $N H A-G I C$ & $100 \%(100+0)$ & $100 \%(100+0)$ & $93.3 \%(86.7+6.7)$ & $93.3 \%(73.3+20)$ & $0.024^{*}$ & 0.210 \\
\hline & RMGIC & $100 \%(100+0)$ & $100 \%(100+0)$ & $93.3 \%(93.3+0)$ & $93.3 \%(86.7+6.7)$ & 0.194 & 0.105 \\
\hline & NHA-RMGIC & $100 \%(100+0)$ & $100 \%(100+0)$ & $93.3 \%(86.7+6.7)$ & $93.3 \%(80+13.3)$ & 0.061 & 0.164 \\
\hline & & $P=N C^{+}$ & $P=N C^{\dagger}$ & $P=0.989$ & $P=0.890$ & & \\
\hline & & Effect size $=\mathbf{N} \boldsymbol{C}^{\dagger}$ & Effect size $=\mathbf{N} \boldsymbol{C}^{\dagger}$ & Effect size $=0.134$ & Effect size $=0.142$ & & \\
\hline \multirow{6}{*}{$\begin{array}{l}\text { Recurrent } \\
\text { caries }\end{array}$} & CGIC & $100 \%(100+0)$ & $100 \%(100+0)$ & $93.3 \%(93.3+0)$ & $93.3 \%(93.3+0)$ & 0.392 & 0.067 \\
\hline & $N H A-G I C$ & $100 \%(100+0)$ & $100 \%(100+0)$ & $93.3 \%(93.3+0)$ & $93.3 \%(93.3+0)$ & 0.392 & 0.067 \\
\hline & RMGIC & $100 \%(100+0)$ & $100 \%(100+0)$ & $93.3 \%(93.3+0)$ & $93.3 \%(93.3+0)$ & 0.392 & 0.067 \\
\hline & NHA-RMGIC & $100 \%(100+0)$ & $100 \%(100+0)$ & $93.3 \%(93.3+0)$ & $93.3 \%(93.3+0)$ & 0.392 & 0.067 \\
\hline & & $P=N C^{+}$ & $P=N C^{t}$ & $P=1.000$ & $P=1.000$ & & \\
\hline & & Effect size $=\mathbf{N} \boldsymbol{C}^{\dagger}$ & Effect size $=N \boldsymbol{C}^{\dagger}$ & Effect size $=0.0000$ & Effectsize $=0.0000$ & & \\
\hline \multirow{6}{*}{$\begin{array}{l}\text { Post-opera- } \\
\text { tive sensitivity }\end{array}$} & CGIC & $100 \%(93.3+6.7)$ & $100 \%(100+0)$ & $93.3 \%(93.3+0)$ & $93.3 \%(93.3+0)$ & 0.392 & 0.067 \\
\hline & $N H A-G I C$ & $100 \%(100+0)$ & $100 \%(100+0)$ & $93.3 \%(93.3+0)$ & $93.3 \%(93.3+0)$ & 0.392 & 0.079 \\
\hline & RMGIC & $100 \%(80+20)$ & $100 \%(100+0)$ & $93.3 \%(93.3+0)$ & $93.3 \%(93.3+0)$ & 0.312 & 0.079 \\
\hline & NHA-RMGIC & $100 \%(93.3+6.7)$ & $100 \%(100+0)$ & $93.3 \%(93.3+0)$ & $93.3 \%(93.3+0)$ & 0.392 & 0.067 \\
\hline & & $P=0.306$ & $P=N C^{+}$ & $P=1.000$ & $P=1.000$ & & \\
\hline & & Effect size $=0.261$ & Effect size $=\mathbf{N} \boldsymbol{C}^{\dagger}$ & Effect size $=0.0000$ & Effectsize $=0.0000$ & & \\
\hline
\end{tabular}

${ }^{*}$ Significant at $P \leq 0.05, N C^{\dagger}$ : Not Computed because the variable is constant. $\%(A+B)=$ Percentages of the total number of restorations assessed at each time period (percentages of Alpha score + Bravo score)

of RMGIC "Fuji II LC, improved" to the tooth structure with Alpha scores of $100 \%$ and 95\%) after 6 months and one year, respectively. The differences in the results might be explained by the carious cervical lesions which were selected for this study rather than the non-carious cervical lesions which were selected for the other studies (Priyadarshini et al. 2017; Hussainy et al. 2018). Therefore, the cavities might be deeper in the present study with subsequent increase in the volume of the restorations. This might result in higher rate of water sorption and more pronounced color change (de Oliveira et al. 2012). Moreover, it was suggested that the color stability of RMGIC was shade dependent (Yap et al. 2006). 
Regarding the surface texture of the restorative materials, the results showed that there was no statistically significant difference among the four tested restorative materials during the 9 months study period. However, there was an increase in the prevalence of Bravo scores and a decrease in prevalence of Alpha scores from; baseline to 3 in NHA-GIC group and from 3 to 6 as well as 6-9 months for all tested restorative materials. These results were in consistence with those of other studies (Folwaczny et al. 2001; Jyothi et al. 2011; Sooraparaju et al. 2014; Hussainy et al. 2018).

The decrease in the quality of the surface texture of CGIC and RMGIC, control or experimental, might be related to the influence of microstructure and mean filler particles size of the restorative materials on its physical properties and abrasion resistance. In the current study, the rough surface texture for the tested RMGIC (Fuji II LC, improved) might be contributed to the larger and irregular filler particles size which were approximately about (4-5 $\mu \mathrm{m})$ (Abdalla et al. 1997; Loguercio et al. 2003; Sidhu 2010; Jyothi et al. 2011; Fagundes et al. 2014; Shikumar et al. 2016; Priyadarshini et al. 2017).

Moreover, this value was much higher than the wavelength of the light (350-750 nm), so these particles scatter light and produce opaque materials (Jyothi et al. 2011; Konde et al. 2012). In addition, conventional GIC (Fuji II Gold Label 2) was found to present larger mean particle sizes, more sensitivity to water sorption and longer setting time than RMGIC, which might be responsible for the high surface roughness obtained by GIC (Pacifici et al. 2013).

Another factor might explain the pitted or rough surface of glass ionomers restorations; in the present study glass ionomer cements were used in "powder and liquid" form rather than "encapsulated" form, which was mandatory to allow for incorporation of NHA in a correct way. Manual mixing might incorporate air bubbles and decrease polymer conversion due to inhibition of the setting reaction by oxygen in the bubbles, which introduces voids and porosity leaving behind a rough, plaque retentive surface and staining (Priyadarshini et al. 2017).

In addition, surface roughness of glass ionomers restorative materials may be related to the final surface resin coating (varnish). This resin coat may represent an area of weakness at the resin coat-GIC interface, especially under-functioning force. This might result in bond failure between the GIC and the overlying coating, which creates a high roughness area and a gap on the restoration surface (Yap et al. 2006).

According to the present study, there was a statistically significant, positive relation between surface texture and color match. This observation is in accordance with another previous study (Nassar et al. 2014). This could be related to the rough surfaces of restorations which positively favor the accumulation of dental plaque and staining from dietary habits, resulting in a change in surface properties of the restorations, such as surface gloss and color stability. Moreover, it has been found that an increase in surface roughness results in an increase in the degree of random reflection of light with subsequent decrease in color properties (Pacifici et al. 2013; Nassar et al. 2014). Regarding the surface staining criterion, results showed that there was no statistically significant change through the study period for any of the restorative materials. Moreover, there was no significant difference between the four materials during the 9 months study period. This observation was similar to that of Jyothi et al. (2011), which might be related to the relatively short follow-up duration as surface staining is usually recorded after long period.

The results showed that there were statistically significant changes in marginal integrity criterion through the study period in the CGIC and NHA-GIC groups. Thus, there was an increase in the prevalence of the Bravo score and a decrease in the prevalence of the Alpha score from 3 to 6 as well as from 6 to 9 months for these groups. At the same time, there was no significant change in marginal integrity through the study period in the RMGIC and NHA-RMGIC groups. This result was in agreement with other previous studies (Franco et al. 2006; Fagundes et al. 2014; Adusumilli et al. 2016; Shikumar et al. 2016; Hussainy et al. 2018).

The differences in the marginal adaptation of CGIC (Fuji GC gold label) in comparison to RMGIC (Fuji II LC, improved), could be explained by the sensitivity of CGIC to humidity in the early period, which increases the solubility of the cement. On the other hand, RMGIC sets by instant resin polymerization, which makes RMGICs more resistant to moisture contamination and hence results in better marginal adaptation (Bapna et al. 2002).

Another reason for the inadequate marginal adaptation in GIC groups could be related to the immediate finishing/polishing procedure of the "one-visit treatment." This immediate finishing/polishing could compromise the marginal seal of GIC to the tooth, as the material is still soft during its initial setting (Fagundes et al. 2014).

Moreover, GIC cervical restorations can be abraded more easily by tooth brushing with dentifrices compared to RMGIC restorations, which exhibit higher resistance to toothbrush wear (Rekha et al. 2012). Also, GICs are more subjected to erosion and microhardness loss over time in comparison to RMGICs. This could be explained by matrix dissolution that occurs in the periphery of the glass particles of CGICs and could result in dissolution of the siliceous hydrogel layer (Rekha et al. 2012; Meral and 
Baseren 2019). All these factors might contribute to the poor marginal adaptation observed in the GICs groups.

Contradictory results to this study have been reported by Sidhu (2010), who found unsatisfactory marginal integrity results for RMGIC restorations. The author attributed that to the hygroscopic expansion of glass ionomer components, which might result in minor marginal fractures at the interface between the tooth and the restoration. This difference in observations could be explained by multiple variables contributed between different study designs that might affect the outcome, such as cavity design, size of restorations and operator variability. Additionally, other factors, such as the bonding capacity of the restorative material, light-curing device and technique, follow-up period, $\mathrm{pH}$ and temperature fluctuation in the patient's mouth could also explain the difference in results between the studies.

There was no significant change in the marginal discoloration criterion through the study period for any of the tested materials. This is in agreement with findings from other studies (Abdalla et al. 1997; Franco et al. 2006; Lee et al. 2010; Sidhu 2010; Perdigão et al. 2012; Fagundes et al. 2014; Adusumilli et al 2016; Shikumar et al. 2016; Priyadarshini et al. 2017; Hussainy et al. 2018). The cavosurface marginal discoloration might be considered a sign of microleakage, which occurs when there are marginal gaps. The absence of marginal discoloration with CGIC and RMGIC, control and experimental groups, was considered as an indication of good bonding of these materials to tooth structure without microleakage (Jyothi et al. 2011).

The results showed absence of failures due to secondary caries with the four tested restorative materials after the 9 months follow-up period. This result is in accordance with other previous studies (Franco et al. 2006; Jyothi et al. 2011; Fagundes et al. 2014). Secondary caries at the margin of the restoration are rarely detected in GIC restorations. This might be related to a demineralization inhibition effect of GICs due to continuous fluoride release over time, which possibly produces a cariostatic action (Dias et al. 2018).

The present clinical trial found no significant difference in post-operative sensitivity among the tested groups during the study period. However, some patients exhibited mild hypersensitivity immediately (at baseline) in the RMGIC, GIC and NHA-RMGIC groups. This finding was in agreement with Gurgan et al. (2015); and Hussainy et al. (2018). Post-operative sensitivity might be attributed to several factors, such as operative trauma, marginal leakage and desiccation. The absence of post-operative sensitivity in the current study may be explained by the absence of marginal leakage together with the clinically acceptable properties of materials that minimize the hydrostatic fluid movement within the dentinal tubules (Hussainy et al. 2018). However, the presence of immediate hypersensitivity (at baseline) may result from mechanical irritation during the restorative procedures or following the finishing and polishing procedure. In this study, the initial hypersensitivity was decreased over time and had disappeared completely at the 3 months follow-up.

In the present study, the cumulative survival rate at the 9 months follow-up for the four tested materials NHAGIC, NHA-RMGIC, CGIC and RMGIC was $100 \%$. This is in agreement with previous short-term evaluations performed with similar restorative materials (Yap et al. 2006; Nassar et al. 2014) or even with long-term evaluations (Loguercio et al. 2003; Franco et al. 2006; Jyothi et al. 2011; Fagundes et al. 2014). These studies found that glass ionomer cement and resin-modified glass ionomer considered the most retentive materials for the management of cervical lesions.

This insignificance difference between the experimental NHA groups and control groups in the current study could be attributed to two main reasons: First, the tested materials may not really differ, but possess similar mechanical and physical properties, and thus show no clinical difference in survival rates. Secondly, a 9 months follow-up period can be considered a very short period to evaluate the long-term clinical behavior of dental restorative materials (Göstemeyer et al. 2016).

Finally, the null hypothesis of the present study was accepted, as the 9 months clinical performance of the modified NHA-GIC and NHA-RMGIC did not differ from that of CGIC and RMGIC. However, further longterm clinical studies are required.

\section{Conclusions}

Within the limitations of the current clinical trial, it could be concluded that there was no benefit of incorporating 5\% NHA into "Fuji GC Gold Label" and "Fuji II LC, improved" regarding their 9 months clinical performance in class $\mathrm{V}$ cavities.

\footnotetext{
Abbreviations

RC: Resin composite; GICs: Glass ionomer cements; RMGIC: Resin-modified glass ionomer cement; USPHS: United States Public Health Service; NHA: Nano-hydroxyapatite particles; TEM: Transmission electron microscopy; FTIR: Fourier transform infrared spectroscopy; XRD: X-ray diffraction; EDX: Elemental dispersive X-ray; NHA-GIC: Nano-hydroxyapatite glass ionomer; NHA-RMGIC: Nano-hydroxyapatite resin-modified glass ionomer; HEMA: Hydroxyethylmethacrylate; TEGDMA: Triethylene-glycol dimethacrylate; TMHMDC: Trimethyl-hexamethylenedicarbonate; MMA: Methyl-methacrylate.
}

\section{Acknowledgements} Not applicable. 


\section{Authors' contributions}

ZMZ, MAN, MHZ and DWE performed the study design. ZMZ performed the whole methodology. ZMZ, MAN, MHZ, SMN and DWE analyzed the data. ZMZ and SMN were the major contributors in writing the manuscript. All the authors read and approved the final manuscript.

\section{Funding}

This trial is funded by the first author and Grant (No. 14-3-4) from the National Research Centre, Cairo, Egypt.

\section{Availability of data and materials}

The authors announce that the data supporting the results of this study are existing within the article.

\section{Declarations}

\section{Ethics approval and consent to participate}

The ethical approval was obtained from the Ethical Research CommitteeNational Research Centre (NRC), Cairo, Egypt (Ref No.: 16039) and from the Faculty of Dental Medicine, Girls branch, Al-Azhar University, Cairo, Egypt (approval code:OPDEN-108-1-i).

\section{Consent for publication}

Institutional consent form was used and presented to the ethical committee before approval.

\section{Competing interests}

No competing interests.

\section{Author details}

${ }^{1}$ Restorative and Dental Materials Department, Oral and Dental Research Institute, National Research Centre, 33 El Bohouth st. (former El Tahrir st.), P.O. 12622, Dokki, Cairo, Egypt. ${ }^{2}$ Conservative Dentistry Department, Faculty of Dental Medicine for Girls, AL-Azhar University, Cairo, Egypt. ${ }^{3}$ Conservative Dentistry Department, Faculty of Oral and Dental Medicine, Misr International University, Cairo, Egypt.

Received: 28 October 2021 Accepted: 6 November 2021 Published online: 21 November 2021

\section{References}

Abdalla A, Alhadainy H, Garcia-Godoy F (1997) Clinical evaluations of glass ionomer and compomers in class $V$ carious lesions. Amer J Dent 10:18-21

Adusumilli H, Avula J, Kakarla P, Bandi S, Mallela G, Vallabhaneni K (2016) Color stability of esthetic restorative materials used in pediatric dentistry: an in vitro study. J Indian Pedod Prevent Dent 34:233-237

Bapna MS, Gadia CM, Drummond JL (2002) Effect of aging and cyclic loading on the mechanical properties of glass ionomer cements. Eur J Oral Sci 110:330-334

Barandehfard F, Kianpour RM, Hosseinnia A, Khoshroo K, Tahriri M, Jazayeri HE et al (2016) The addition of synthesized hydroxyapatite and fluorapatite nanoparticles to a glass-ionomer cement for dental restoration and its effects on mechanical properties. Ceram Int 42:17866-17875

Boing TF, de Genus JL, Wambier LM, Loguercio AD, Reis A, Gomess OM (2018) Are glass-ionomer restorations in cervical lesions more long-lasting than resin-based composite resins? A systematic review and meta-analysis. J Adhes Dent 19:1-18

Burgess JO, Gallo JR, Ripps AH, Walker RS, Ireland EJ (2004) Clinical evaluation of four Class 5 restorative materials: 3-year recall. Am J Dent 17(3):147-150

Cardoso MV, Delmé KI, Mine A, Neves A, Coutinho E, De Moor R et al (2010) Towards a better understanding of the adhesion mechanism of resin modified glass-ionomer by bonding to differently prepared dentin. J Dent 38:921-929

de Oliveira FG, Machado LS, Rocha EP, Briso A, de Alexandre RS, Sundefeld ML et al (2012) Clinical evaluation of a composite resin and a resin modified glass ionomer cement in non-carious cervical lesions: one-year results. IJCD 5:1-1
Dias AG, Magno MB, Delbem AC, Cunha RF, Maia LC, Pessan JP (2018) Clinical performance of glass ionomer cement and composite in class II restorations in primary teeth: a systematic review and meta-analysis. J Dent 73:1-13

Fagundes TC, Barata TJ, Bresciani E, Santiago SL, Franco EB, Lauris JRP et al (2014) Seven-year clinical performance of resin composite versus resinmodified glass ionomer restorations in non-carious cervical lesions. Oper Dent 39:578-587

Folwaczny M, Loher C, Mehl A, Kunzelman K, Hickel R (2001) Class V lesions restored with four different tooth-colored materials: 3-year results. Clini Oral Investig 5:31-39

Franco EB, Benetti AR, Ishikiriama SK, Santiago SL, Lauris JR, Jorge MF et al (2006) 5-year clinical performance of resin composite versus resin modified glass ionomer restorative system in non-carious cervical lesions. Oper Dent 31:403-408

Göstemeyer G, Blunck U, Sebastian P, Schwendicke F (2016) Design and validity of randomized controlled dental restorative trials. Materials (basel) 9:372-380

Gurgan S, Kutuk ZB, Erin E, Oztas SS, Cakir FY (2015) Four-year randomized clinical trial to evaluate the clinical performance of a glass ionomer restorative system. Oper Dent 40:1-10

Hussainy SN, Nasim I, Thomas T, Ranjan M (2018) Clinical performance of resinmodified glass ionomer cement, flowable composite and polyacid-modified resin composite in non-carious cervical lesions: one-year follow-up. J Conserv Dent 21:510-515

Jyothi K, Annapurna S, Kumar AS, Venugopal P (2011) Clinical evaluation of giomer and resin-modified glass ionomer cement in Class $V$ non-carious cervical lesion: an in vivo study. J Conserv Dent 14:409-413

Kantharia N, Naik S, Apte S, Kheur M, Kheur S, Kale B (2014) Nano-hydoxyapatite and its contemporary applications: review article. J Dent Res Sci Dev 1:15-19

Kharma K, Zogheib T, Bhandi S, Mehanna C (2018) Clinical evaluation of microhybrid composite and glass ionomer restorative material in permanent teeth. J Contemp Dent Pract 9:226-232

Khoroushi M, Keshani F (2013) A review of glass ionomers: from conventional glass ionomer to bioactive glass ionmer. Dent Res J 10:411-420

Khurshid Z, Zafar M, Qasim S, Shahab S, Naseem M, Abu-Reqaiba A (2015) Advances in nanotechnology for restorative dentistry. Materials 8:717-731

Konde S, Raj S, Jaiswal D (2012) Clinical evaluation of a new art material: nanoparticulated resin-modified glass ionomer cement. J Int Soc Prev Community Dent 2:42-47

Lee JJ, Lee YK, Choi BJ, Lee JH, Choi HJ, Son HK et al (2010) Physical properties of resin-reinforced glass ionomer cement modified with micro and nanohydroxyapatite. J Nanosci Nanotechnol 10:5270-5276

Loguercio AD, Reis A, Barbosa AN, Roulet JF (2003) Five-year double-blind randomized clinical evaluation of a resin-modified glass ionomer and a polyacid-modified resin in non-caries cervical lesions. J Adhes Dent 5:323-332

Mahn E, Rousson V, Heintze S (2015) Meta-Analysis of the influence of bonding parameters on the clinical outcome of tooth-colored cervical restorations. J Adhes Dent 17:391-403

Meral E, Baseren NM (2019) Shear bond strength and microleakage of novel glass-ionomer cements: an in-vitro study. Niger J Clin Pract 22:566-572

Najeeb S, Khurshid Z, Zarfar M, Khan A, Zohaib S, Marti J et al (2016) Modifications in glass ionomer cements: nano-sized fillers and bioactive nanoceramics. Int J Mol Sci 17:1134-1150

Nassar AM, Abdalla Al, Shalaby ME (2014) One year clinical follow up of nano filled glass ionomer and composite resin restorations. Tanta Dent J $11: 21-35$

Pacifici E, Bossú M, Giovannetti A, Torre GL, Guerra F, Polimeni A (2013) Surface roughness of glass ionomer cements indicated for uncooperative patients according to surface protection treatment. Ann Stomatol (roma) 4:250-258

Perdigão J, Dutra-Corrêa M, Saraceni SH, Ciaramicoli MT, Kiyan VH (2012) Randomized clinical trial of two resin-modified glass ionomer materials: 1-year results. Oper Dent 37:591-601

Perez CR (2010) Alternative technique for class $V$ resin composite restorations with minimum finishing/polishing procedures. Oper Dent 35(3):375-379 
Poorzandpoush K, Omrani LR, Jafarnia SH, Golkar P, Atai M (2017) Effect of addition of nano hydroxyapatite particles on wear of resin modified glass ionomer by tooth brushing simulation. J Clin Exp Dent 9:372-376

Priyadarshini B, Jayaprakash T, Nagesh B, Sunil C, Sujana V, Deepa V (2017) One-year comparative evaluation of Ketac Nano with resin-modified glass ionomer cement and giomer in noncarious cervical lesions: a randomized clinical trial. J Conserv Dent 20:204-209

Rekha CV, Varma B, Jayanthi C (2012) Comparative evaluation of tensile bond strength and micrleakage of conventional glass ionomer cement, resin modified glass ionomer cement and compomer: an in vitro study. Contemp Clin Dent 3:282-287

Shikumar G, Naiza E, Mookambika R, Aanchal A (2016) Newer advances in glass ionomer cement: a review. Ann Essences Dent 8:19-23

Sidhu SK (2010) Clinical evaluations of resin-modified glass-ionomer restorations. Dent Mater 26:7-12

Singh MTR, Suresh P, Sandhyarani J, Sravanthi J (2011) Glass ionomer cements (GIC) in dentistry: a review. IJPAES 1:26-30

Sooraparaju SG, Kanumuru PK, Nujella SK, Konda KR, Reddy BK, Penigalapati $S$ (2014) A comparative evaluation of microleakage in class $V$ composite restorations. Int J Dent 2014:1-4

Stewardson D, Creanor S, Thornley P, Bigg T, Bromage C, Browne A, Cottam D, Dalby D, Gilmour J, Horton J, Roberts E, Westoby L, Burke T (2012) The survival of class $\vee$ restorations in general dental practice: part 3, five-year survival. Brit Dent J 212:E14

Yap AU, Lye KW, Sau CW (2006) Effects of aging on repair of resin-modified glass ionomer cements. J Oral Rehabil 27:422-427

\section{Publisher's Note}

Springer Nature remains neutral with regard to jurisdictional claims in published maps and institutional affiliations.

\section{Submit your manuscript to a SpringerOpen ${ }^{\circ}$ journal and benefit from:}

- Convenient online submission

- Rigorous peer review

- Open access: articles freely available online

- High visibility within the field

- Retaining the copyright to your article

Submit your next manuscript at $\boldsymbol{\nabla}$ springeropen.com 